Arq. Bras. Med. Vet. Zootec., v.69, n.6, p.1607-1614, 2017

\title{
Teofilina como agente capacitante do sêmen bovino
}

\author{
[Theophylline as a capacitating agent of bovine semen] \\ F.C. Varago $^{1}$, L.P. Silva ${ }^{2}$, J.R. Ribeiro ${ }^{2}$, C.A. Fernandes ${ }^{1}$, B.C. Carvalho ${ }^{3}$, \\ M. M. Gioso ${ }^{1}$, V.S. Moustacas ${ }^{4}$ \\ ${ }^{1}$ Universidade José do Rosário Vellano - Unifenas - Alfenas, MG \\ ${ }^{2}$ Aluna de pós-graduação - Universidade José do Rosário Vellano - Unifenas - Alfenas, MG \\ ${ }^{3}$ Pesquisador Embrapa Gado de Leite - Juiz de Fora, MG \\ ${ }^{4}$ Analista Embrapa Agrossilvipastoril - Sinop, MT
}

\begin{abstract}
RESUMO
Objetivou-se avaliar a teofilina como agente capacitante substituto ou associado à heparina sobre a reação acrossômica dos espermatozoides e o desenvolvimento de embriões produzidos in vitro. $\mathrm{O}$ experimento foi realizado com quatro touros e três tratamentos, totalizando 12 grupos experimentais. O sêmen dos touros foi avaliado nos tratamentos descritos a seguir: tratamento 1 (HEP): heparina $-10 \mu \mathrm{g} / \mathrm{mL}$; tratamento 2 (TEO): teofilina - 5mM; tratamento 3 (HEP + TEO): heparina $(10 \mu \mathrm{g} / \mathrm{mL})+$ teofilina $(5 \mathrm{mM})$, por zero, seis, 12 e 18 horas, corados com trypan blue/Giemsa para avaliação da reação acrossômica. Para a produção dos embriões, os agentes capacitantes foram adicionados aos meios de fertilização. Na análise espermática, a taxa de reação acrossômica verdadeira foi maior $(\mathrm{P}<0,05)$ no tempo zero hora, enquanto para espermatozoides mortos, as maiores taxas $(\mathrm{P}<0,05)$ foram nos tempos de $12 \mathrm{~h}$ $(84,46 \pm 5,82)$ e $18 \mathrm{~h}(86,75 \pm 4,19)$. A taxa de embriões produzidos $(37,97 \pm 13)$ e a taxa de eclosão $(33,50 \pm 14)$ foram maiores $(\mathrm{P}<0,05)$ para o tratamento HEP. Não foi observada diferença $(\mathrm{P}>0,05)$ entre touros na análise de reação acrossômica nem na PIVE. A utilização da teofilina foi tão eficiente quanto a da heparina na indução da reação acrossômica, no entanto resultou em menores taxas de produção embrionária.
\end{abstract}

Palavras-chave: fertilização, reação acrossômica, espermatozoide, metilxantinas

\begin{abstract}
The sperm capacitating process should take special attention during in vitro embryo production (IVEP) once that affects the success of embryo production. The study aimed to evaluate theophylline as substitute capacitating agent or in combination with heparin on the sperm acrosome reaction and development of embryos produced in vitro. The experiment was carried out using 4 bulls and 3 treatments, establishing 12 experimental groups. Each bull was evaluated in the following treatments: Treatment 1 (HEP): Heparin - 10mg/mL; Treatment 2 (THEO): Theophylline - 5mM; Treatment 3 (HEP + THEO), Heparin $(10 \mathrm{mg} / \mathrm{mL})+$ Theophylline $(5 \mathrm{mM})$. The semen of bulls was incubated in each treatment for 0, 6, 12 and 18h, stained with Trypan blue / Giemsa and analyzed by electron microscopy for assessment of acrosome reaction. Using sperm of same bulls, capacitating agents were added to the fertilization media, for IVEP. In sperm analysis, the true acrosome reaction rate was higher $(P<0.05)$ in time $0 h$, while sperm dead rates were highest $(P<0.05)$ at $12 \mathrm{~h}(84.46 \pm 5,82)$, and $18 \mathrm{~h}(86.75 \pm 4.19)$. The produced embryos rate $(37.97 \pm 13)$ and hatching rate $(33.50 \pm 14)$ were larger $(P<0.05)$ for HEP treatment. There was no difference $(P>0.05)$ between bulls in acrosome reaction analysis neither for IVEP. The use of theophylline was as effective as heparin in the induction of the acrosome reaction, although it resulted in lower embryo production rates.
\end{abstract}

Keywords: fertilization, acrossome reaction, sperm, methylxanthine

Recebido em 28 de julho de 2016

Aceito em 22 de fevereiro de 2017

E-mail: varagovet@hotmail.com 


\section{INTRODUÇÃO}

A capacitação deve receber especial atenção durante a produção in vitro de embriões (PIVE), já que, em condições fisiológicas, os espermatozoides, obrigatoriamente, sofrem esse processo durante a passagem pelo trato genital da fêmea, para se tornarem aptos à fecundação (Gordon, 1994). O processo de capacitação natural ocorre pela ação de componentes presentes na tuba uterina, como os glicosaminoglicanos, os quais vão induzir mudanças no espermatozoide. O glicosaminoglicano mais utilizado em laboratórios de PIVE bovinos para induzir a capacitação espermática é a heparina (Parrish et al., 1988). A ligação da heparina se dá por uma série de proteínas do plasma seminal bovino, que se prendem ao espermatozoide na ejaculação e interagem com o colesterol e os fosfolipídeos da membrana plasmática. Após a ligação à heparina, há perda de componentes da superfície do espermatozoide, incluindo perda da lecitina, das proteínas do plasma seminal, do colesterol e dos fosfolipídeos (Manjunath e Therien, 2002). Outras alterações relacionadas à ligação da heparina na célula espermática incluem alterações do pH intracelular, do cálcio intracelular e dos níveis de adenosina monofosfato cíclico (AMPc) (Parrish, 2014).

No entanto, touros podem ter diferentes respostas quanto à capacitação in vitro, o que explica, em parte, o fato de que nem todos os espermatozoides submetidos ao processo de fertilização in vitro (FIV) apresentam bons resultados quanto à produção de embriões (Folhadela, 2008). Essa diferença pode estar relacionada à falha da indução da capacitação in vitro pela heparina, o que justifica a procura de um agente que possa proporcionar maior capacitação espermática quando utilizado associado ou não à heparina. As metilxantinas, que inibem as fosfodiesterases aumentando os níveis de AMPc, além de promoverem efeito na concentração de cálcio intracelular (Pauwels et al., 2001), desempenhariam um papel de desencadeadores da capacitação. A teofilina, uma metilxantina que possui ação mais potente que a cafeína, de acordo com dois estudos encontrados na literatura, pode aumentar a capacidade dos espermatozoides em se ligar a oócitos maturados in vitro tanto na espécie bovina (Takahashi e First,1993) quanto na suína (Yoshioka et al., 2003).

Nesse sentido, o objetivo do presente estudo foi testar a teofilina como possível agente de capacitação na espécie bovina, bem como a sua associação com a heparina no desenvolvimento de embriões produzidos in vitro e na indução da reação acrossômica dos espermatozoides.

\section{MATERIAL E MÉTODOS}

Todos os meios utilizados para a produção dos embriões foram adquiridos da empresa Biodux (Campinas, SP, Brasil). A teofilina foi adquirida da Sigma-Aldrich (T1633).

Após a avaliação do sêmen de 11 touros por meio das análises de motilidade e vigor, morfologia e integridade funcional da membrana plasmática pelo teste hiposmótico (HO), não foi observada coerência entre os parâmetros avaliados em cada reprodutor. Diante da impossibilidade de encontrar um ou dois touros com desempenho superior ou inferior em todas as características seminais e uma vez que, para algumas variáveis, como a motilidade, muitos touros tiveram igual desempenho, a seleção dos touros foi baseada no parâmetro morfologia. A morfologia, segundo Barth e Oko (1989), possui relação direta com a fertilidade e, também por esta razão, foi o parâmetro considerado na seleção dos touros a serem testados. O exame morfológico foi realizado em câmara úmida em contraste de fase (1000x), contando-se 200 células por avaliação, com três repetições por animal, e, ao final, a porcentagem de defeitos maiores e menores foi contabilizada (Barth e Oko, 1989). Com base nesse critério, foram selecionados os dois touros superiores A e C (menor porcentagem de defeitos) e dois inferiores $B$ e D (maior porcentagem de defeitos).

Experimento 1. O primeiro experimento foi conduzido para avaliar da taxa de reação acrossômica do sêmen na presença dos agentes de capacitação adicionados aos meios de fertilização, constituindo os tratamentos: tratamento 1 (HEP): heparina - $10 \mu \mathrm{g} / \mathrm{mL}$; tratamento 2 (TEO): teofilina $-5 \mathrm{mM}$; tratamento 3 (HEP + TEO): heparina $(10 \mu \mathrm{g} / \mathrm{mL})+$ teofilina $(5 \mathrm{mM})$. A concentração de $10 \mu \mathrm{g} / \mathrm{mL}$ de heparina foi escolhida baseada na rotina de produção da 
maioria dos laboratórios comerciais de FIV. A concentração de teofilina foi escolhida baseada no estudo de Takahashi e First (1993), que relataram um aumento da capacidade fertilizante dos espermatozoides e do processo de FIV em bovinos com a concentração de $5 \mathrm{mM}$ de teofilina.

Após descongelamento e seleção por gradiente de Percoll 90 e $45 \%$ como descrito por Parrish et al. (1995), o sêmen foi incubado em meio de fertilização de acordo com os tratamentos HEP, TEO, HEP + TEO, na concentração de $2 \times 10^{6}$ espermatozoides $/ \mathrm{mL}$, em incubadora a $38,8^{\circ} \mathrm{C}$, $5 \%$ de $\mathrm{CO}_{2}$ e umidade saturada, na ausência de oócitos. Uma amostra de cada reprodutor foi submetida à técnica de coloração imediatamente após o descongelamento e novamente a cada seis horas de incubação, sendo as análises realizadas às zero, seis, 12 e 18 horas.

A integridade do acrossomo foi avaliada empregando-se a técnica de dupla coloração (trypan blue/Giemsa - TBG) descrita por Didion et al. (1989). O sêmen foi incubado na proporção 1:1 com trypan blue 0,2\%, em banho-maria, a $37^{\circ} \mathrm{C} / 15 \mathrm{~min}$, seguido de adição de $8 \mathrm{~mL}$ de DPBS (Dulbecco's Phosphate Buffered Saline) e centrifugação a $700 \mathrm{~g}$ por $6 \mathrm{~min}$. Do pellet formado, foram feitos esfregaços em lâminas, que foram coradas com solução de Giemsa a 5\%, por cerca de $60 \mathrm{~min}$, e posteriormente lavadas e secas ao ar. As análises foram realizadas em duplicata. A leitura foi realizada em microscópio de campo claro com aumento de 1000x, contando-se 200 células em cada lâmina para avaliação das seguintes características: reação acrossômica verdadeira - acrossomo e região pós-acrossomal não coradas; reação acrossômica falsa - acrossomo não corado e região pósacrossomal corada em azul; mortos - corados em azul pelo trypan blue na região pós-acrossomal e acrossomo corado em roxo ou rosa pelo Giemsa.

Experimento 2. O segundo experimento foi conduzido para avaliar a produção embrionária, utilizando-se os agentes de capacitação na fertilização. Foram utilizados ovários obtidos em matadouros. Os folículos ovarianos entre 3 e $8 \mathrm{~mm}$ de diâmetro foram aspirados com auxílio de seringa de $10 \mathrm{~mL}$ acoplada à agulha $40 \mathrm{x}$ $12 \mathrm{~mm}$. Os complexos cumulus-oócitos (COCs) imaturos classificados como "viáveis", de acordo com Viana et al. (2004), foram cultivados em
TCM 199 (Earle), suplementado com 10\% de soro fetal bovino, piruvato $(22 \mu \mathrm{g} / \mathrm{mL})$, hormônio luteinizante $(50 \mu \mathrm{g} / \mathrm{mL})$, hormônio folículo estimulante $(0,5 \mu \mathrm{g} / \mathrm{mL})$ e os antibióticos penicilina e gentamicina $(50 \mu \mathrm{g} / \mathrm{mL}$ de cada) sob óleo mineral.

Decorridas 24 horas, os COCs foram coincubados com espermatozoides selecionados por gradiente de Percoll (Parrish et al., 1995) na concentração $2 \times 10^{6}$ espermatozoides $/ \mathrm{mL}$, em meio de fecundação suplementado com gentamicina e penicilina $(50 \mu \mathrm{g} / \mathrm{mL}$ de cada), penicilamina $(2,7 \mu \mathrm{g} / \mathrm{mL})$, hipotaurina $(1 \mu \mathrm{g} / \mathrm{mL})$, epinefrina $(0,3 \mu \mathrm{g} / \mathrm{mL})$, albumina sérica bovina $8806(5 \mu \mathrm{g} / \mathrm{mL})$ e piruvato $(22 \mu \mathrm{g} / \mathrm{mL})$, sob óleo mineral. Ao meio de FIV, foram adicionados os agentes de capacitação, que constituíram os tratamentos HEP, TEO e HEP +TEO, como já descrito no experimento 1 . $\mathrm{O}$ dia da fecundação foi considerado como o dia zero (D0). Após 12 horas, os possíveis zigotos foram incubados em meio synthetic oviductal fluid (SOF) suplementado com inositol $(0,5 \mu \mathrm{g} / \mathrm{mL})$ e tricitrato de sódio $(0,1 \mu \mathrm{g} / \mathrm{mL})$. Foram realizadas 10 repetições (baterias de produção de embriões). As taxas de clivagem, produção embrionária e eclosão foram avaliadas aos dois, sete e 10 dias após a fecundação, respectivamente. Todos os procedimentos foram realizados em incubadora contendo $5 \%$ de $\mathrm{CO}_{2} \mathrm{e}$ umidade saturada a $38,8^{\circ} \mathrm{C}$.

Todos os dados foram verificados quanto à normalidade e à homogeneidade de variância (Proc Univariate). No experimento 1, os dados foram submetidos à análise de variância, sendo utilizado modelo linear generalizado (Proc GLM), considerando-se os efeitos fixos de tratamento, tempo e sua interação. $\mathrm{Na}$ análise, o efeito de tempo foi modelado como medida repetida. No experimento 2 , os dados referentes às taxas de clivagem, blastocisto e eclosão, obtidas de 10 repetições, foram analisados e submetidos à análise de variância, utilizando-se modelo misto (Proc Mixed), sendo considerados os efeitos fixos de tratamento, touro e sua interação. Foi considerado o efeito aleatório de touro dentro de cada repetição. As médias de quadrados mínimos foram comparadas pelo teste de Tukey-Kramer $(\mathrm{P}<0,05)$. Todos os procedimentos foram realizados utilizando-se o programa estatístico SAS, versão 9.2 (Statistical analysis system, 2008). 


\section{RESULTADOS}

Experimento 1. Na avaliação da reação acrossômica, não houve diferença $(\mathrm{P}>0,05)$ quanto à classificação espermática em função dos três tratamentos, como observado na Tab. 1.

A reação acrossômica verdadeira foi maior $(\mathrm{P}<0,05)$ no tempo zero hora em relação aos tempos de seis, 12 e 18 horas, como observado na Tab. 2. Para a reação acrossômica falsa, não houve diferença $(\mathrm{P}>0,05)$ entre os tempos de incubação, descritos na Tab. 2. Foi observada maior taxa $(\mathrm{P}<0,05)$ de espermatozoides classificados como mortos nos tempos de $12 \mathrm{~h}$ e $18 \mathrm{~h}$ em comparação aos tempos de seis horas e zero hora, de acordo com a Tab. 2.

Experimento 2. A taxa de clivagem não diferiu (P>0,05) entre os três tratamentos (Tab. 3). A taxa de embriões produzidos, bem como a taxa de eclosão (Tab. 3), foram maiores $(\mathrm{P}<0,05)$ para o tratamento heparina em relação aos tratamentos teofilina e heparina + teofilina.

Não houve efeito de touro nas taxas de clivagem, embriões produzidos e eclosão $(\mathrm{P}>0,05)$, como observado na Tab. 4.

Tabela 1. Classificação espermática relativa à ocorrência de reação acrossômica após coloração dupla trypan blue/ Giemsa, em função do tratamento

\begin{tabular}{lccc}
\hline \multirow{2}{*}{ Tratamento } & \multicolumn{3}{c}{ Classificação espermática } \\
\cline { 2 - 4 } & $\begin{array}{c}\text { Reação acrossômica } \\
\text { verdadeira }(\%)\end{array}$ & $\begin{array}{c}\text { Reação acrossômica } \\
\text { falsa }(\%)\end{array}$ & Mortos $(\%)$ \\
\hline Heparina & $25,7 \pm 23,3$ & $8,6 \pm 3,0$ & $63,3 \pm 23,5$ \\
Teofilina & $21,7 \pm 24,8$ & $7,7 \pm 3,4$ & $70,4 \pm 25,8$ \\
Heparina + & $24 \pm 24,3$ & $6,7 \pm 3,1$ & $69,2 \pm 25,4$ \\
Teofilina & & \\
\hline Médias analisadas pelo teste Tukey-Kramer (P>0,05) (Statistical...,2008). Resultados expressos em média \pm erro- \\
padrão.
\end{tabular}

Tabela 2. Classificação espermática relativa à ocorrência de reação acrossômica após coloração dupla trypan blue/Giemsa em função do tempo

\begin{tabular}{cccc} 
& \multicolumn{3}{c}{ Classificação espermática } \\
\cline { 2 - 4 } Tempo (hs) & $\begin{array}{c}\text { Reação acrossômica } \\
\text { verdadeira (\%) }\end{array}$ & $\begin{array}{c}\text { Reação acrossômica } \\
\text { falsa (\%) }\end{array}$ & Mortos $(\%)$ \\
\hline 0 & $61,5 \pm 6,7^{\mathrm{A}}$ & $9,1 \pm 3,7$ & $29,3 \pm 4,5^{\mathrm{C}}$ \\
6 & $19,6 \pm 12,7^{\mathrm{B}}$ & $7,2 \pm 3,1$ & $72,7 \pm 13,0^{\mathrm{B}}$ \\
12 & $7,2 \pm 4,4^{\mathrm{C}}$ & $8,3 \pm 3,0$ & $84,4 \pm 5,8^{\mathrm{A}}$ \\
18 & $7,0 \pm 2,6^{\mathrm{C}}$ & $6,2 \pm 2,5$ & $86,7 \pm 4,1^{\mathrm{A}}$ \\
\hline
\end{tabular}

Letras na coluna diferem pelo teste Tukey-Kramer $(\mathrm{P}<0,05)$ (Statistical..., ano). Resultados expressos em média \pm erro-padrão.

Tabela 3. Taxas de clivagem, produção embrionária e eclosão em função de tratamento

$\begin{array}{lcccc} & \text { Oócitos } & \begin{array}{c}\text { Taxa de clivagem } \\ (\%)\end{array} & \begin{array}{c}\text { Taxa de embriões } \\ \text { produzidos }(\%)\end{array} & \text { Taxa de eclosão (\%) } \\ \begin{array}{lccc}\text { Heparina } \\ \text { Teofilina }\end{array} & 609 & 60,5 \pm 15,5 & 37,9 \mathrm{~A} \pm 13,1 & 33,5 \mathrm{~A} \pm 14,0 \\ \begin{array}{l}\text { Heparina }+ \\ \text { Teofilina }\end{array} & 880 & 62,1 \pm 15,6 & 28,5 \mathrm{~B} \pm 10,1 & 22,8 \mathrm{~B} \pm 10,7 \\ \text { Média geral } & 68,0 \pm 19,0 & 27,6 \mathrm{~B} \pm 11,3 & 23,0 \mathrm{~B} \pm 10,4 \\ & & 61,4 \pm 16,6 & 31,4 \pm 12,4 & 26,5 \pm 12,7\end{array}$

Letras na coluna diferem pelo teste Tukey-Kramer $(\mathrm{P}<0,05)$ (Statistical..., ano). Resultados expressos em média \pm desvio-padrão. 
Teofilina como agente...

Tabela 4. Taxas de clivagem, produção embrionária e eclosão em função de touro

\begin{tabular}{lcccc} 
& Oócitos & Taxa de clivagem $(\%)$ & $\begin{array}{c}\text { Taxa de embriões } \\
\text { produzidos }(\%)\end{array}$ & $\begin{array}{c}\text { Taxa de eclosão } \\
(\%)\end{array}$ \\
\hline Touro A & 687 & $64,1 \pm 13,0$ & $31,7 \pm 13,9$ & $26,9 \pm 14,2$ \\
Touro B & 662 & $56,7 \pm 16,8$ & $30,0 \pm 11,0$ & $26,7 \pm 11,0$ \\
Touro C & 663 & $64,0 \pm 15,4$ & $33,9 \pm 12,3$ & $27,3 \pm 13,0$ \\
Touro D & 661 & $61,26 \pm 20,2$ & $29,7 \pm 12,2$ & $24,8 \pm 13,0$ \\
\hline
\end{tabular}

Médias analisadas pelo teste Tukey-Kramer $(\mathrm{P}>0,05)$ (Statistical..., ano). Resultados expressos em média \pm desviopadrão.

\section{DISCUSSÃO}

Experimento 1. Sabendo-se que a coloração dupla de trypan blue/Giemsa é empregada para estimar o potencial de fecundação de amostras de sêmen destinadas à FIV ou à inseminação artificial (Tartaglione e Ritta, 2004), observou-se que, contrariamente ao que se esperava, a teofilina ou a sua associação com a heparina não foram eficientes em aumentar a taxa de reação acrossômica verdadeira em bovinos. Ainda foi possível observar que, independentemente do agente de capacitação, a incidência de reação acrossômica verdadeira foi relativamente baixa em comparação ao índice de espermatozoides mortos (Tab. 1). Isso pode ser decorrente do tempo total de incubação (18 horas), o que pode ser diretamente constatado ao se avaliarem os resultados de reação acrossômica em função do tempo (Tab. 2), com grande morte espermática já às seis horas de incubação. De acordo com relatos de Parrish et al. (1985), a taxa de fecundação e a reação acrossômica são dependentes do tempo de exposição dos espermatozoides à heparina, uma vez que, após duas horas de incubação, ocorre saturação das ligações da heparina com as células espermáticas, impedindo que haja um aumento da taxa de fecundação em um maior tempo de incubação. Alguns autores relatam que não houve diferença da frequência de reação acrossômica entre quatro, cinco e oito horas de incubação com a heparina, enquanto outros, ao compararem os tempos de incubação de quatro, seis e nove horas, observaram que o período de seis horas apresentou os melhores resultados (Assumpção et al., 2002). No presente estudo, as avaliações foram realizadas em intervalo maior de tempo (a cada seis horas), de forma que não é possível concluir se houve aumento na incidência de reação acrossômica a cada hora, com início de queda em determinado ponto. Uma vez que o número de espermatozoides mortos foi bastante elevado, já às seis horas de incubação, é possível que o cultivo de espermatozoides na ausência de COCs e dos fatores de crescimento secretados por esses, que são capazes de desencadear o estímulo da reação acrossômica (Meizel e Turner, 1996), prejudicaram a viabilidade espermática in vitro.

Experimento 2. Segundo Gordon (1994), no sistema de produção embrionária in vitro, podem-se esperar valores entre 60 e $90 \%$ de taxa de clivagem e entre 25 e $40 \%$ de embriões (i.e., $60,7 \%$ e $36,5 \%$ de clivagem e produção embrionária, respectivamente - Pugh et al., 2000). Os resultados observados no presente estudo (Tab. 3) para os parâmetros acima citados estão dentro do reportado na literatura, o que evidencia condições adequadas de produção.

Quando comparados os grupos experimentais, a produção embrionária para os tratamentos que continham teofilina foi menor que a observada para o tratamento heparina (Tab. 3). Aparentemente, a teofilina isolada ou associada à heparina não induziu boa capacitação espermática, o que acarretaria diminuição no índice de fertilização, resultando em menor taxa de produção embrionária. Porém, a taxa de clivagem não diferiu entre os grupos, e os resultados encontrados por meio da coloração espermática pós-incubação do sêmen com os agentes capacitantes (Tab. 1 - experimento 1) corroboram os achados da taxa de clivagem, ou seja, não foram observadas diferenças no índice de espermatozoides com reação acrossômica verdadeira entre os tratamentos. Desse modo, a diferença de produção embrionária entre os grupos pode ser atribuída ao fato de que nem todos os oócitos que sofreram clivagem foram competentes em sustentar o desenvolvimento embrionário até o estágio de blastocisto. Três possíveis explicações podem ser discutidas. Inicialmente, essa menor produção embrionária pode estar relacionada aos espermatozoides, pois, de acordo com Coelho et al. (1998), a 
fertilidade do sêmen pode ser atribuída a dois principais fatores: a capacidade de fecundação e a competência de desenvolvimento pósfecundação. Nesse caso, é possível que a teofilina, mesmo induzindo uma boa resposta quanto à capacitação e à taxa de fecundação, tenha sido tóxica ao DNA do espermatozoide, o que impossibilitou sustentar o desenvolvimento até a fase de pré-implantação.

Além disso, a presença de teofilina no meio de fecundação pode ter aumentado a incidência de fecundações anormais, principalmente polispermia, durante a FIV (Chian et al., 1992). De fato, o aumento da polispermia tende a diminuir a taxa de fecundação monospermática e a aumentar a taxa de clivagem, porém os embriões clivados provenientes de fecundação polispermática, frequentemente, não se desenvolvem até o estágio de blastocisto, por terem vindos de fecundação anormal (Ramos et al., 2000), o que poderia explicar os achados do presente estudo com o uso da teofilina isolada ou associada à heparina. Foi relatado por Tesarik et al. (1992) que a atividade máxima das metilxantinas é alcançada após 10 minutos e que essa fase ativa é de menos de duas horas, ou seja, seu efeito é a curto prazo. Tal resultado foi comprovado por Takahashi e First (1993), os quais concluíram que a teofilina acelera o processo de FIV em bovinos. Desse modo, acredita-se que a teofilina possa ter causado a polispermia ao potencializar a capacitação espermática, induzindo à alta concentração de espermatozoides capacitados de uma só vez. Como relatado por Ramos et al. (2000), em altas concentrações espermáticas, possivelmente existe alto teor de enzimas hidrolíticas liberadas pela presença de espermatozoides, o que facilita a ocorrência da polispermia, já que tais enzimas em excesso podem auxiliar na penetração de mais de um espermatozoide.

Finalmente, a incubação com teofilina pode ter prejudicado a ativação do genoma embrionário (AGE), com consequências para a transição materno-zigótica, resultando em aumento de bloqueio do desenvolvimento embrionário. Sabese que a transcrição materno-zigótica, processo caracterizado pela iniciação da transcrição no embrião e substituição do RNAm materno pelo RNAm embrionário, envolve eventos morfológicos e fisiológicos, como a formação do zigoto, a AGE e a diferenciação celular durante a formação do blastocisto. Como a AGE só ocorre mais tardiamente no desenvolvimento embrionário, após a independência dos genes maternos presentes no oócito, que são responsáveis por manter o desenvolvimento inicial (Memili et al., 1998), essa alteração não seria percebida na avaliação da taxa de clivagem. Para confirmar essa possibilidade, seria necessária uma avaliação diária do desenvolvimento para constatação do número de estruturas que pararam seu desenvolvimento no estágio de oito para 16 células, quando ocorre a AGE em bovinos (Souza et al., 1998), o qual está associado ao bloqueio do desenvolvimento embrionário. Entretanto, o sucesso nessa fase de desenvolvimento não é frequentemente reportado e não foi avaliado no presente estudo.

Apesar de, no presente estudo, a teofilina ter resultado em menor produção embrionária, esse agente produziu resultados satisfatórios em suínos, quando Yoshioka et al. (2003), ao utilizarem $2,5 \mathrm{mM}$ de teofilina no meio de capacitação, encontraram 74,0 77,0 de taxa de clivagem, enquanto na concentração de $1,25 \mathrm{mM}$, a taxa de clivagem foi de 71,5 $\pm 7,5$. Kang et al. (2015), quando trabalharam com uma concentração de $2,5 \mathrm{mM}$ de teofilina em combinação com uma mistura de PHE (penicilamina, hipotaurina e epinefrina), constataram que essa associação acelerou a motilidade e a penetração espermática em oócitos bovinos e resultou em taxas de fertilização e de blastocisto esperadas. No entanto, esses autores não testaram outras concentrações de teofilina. Takahashi e First (1993), ao estudarem diferentes concentrações de teofilina, obtiveram melhores taxas de produção em bovinos com $2,5 \mathrm{mM}$ e $5 \mathrm{mM}$, e concluíram que essas concentrações aumentaram a capacidade fecundante dos espermatozoides. Tais resultados sinalizam a possibilidade, também na espécie bovina, de que melhores resultados possam ser obtidos com menores doses de teofilina.

\section{CONCLUSÃO}

A teofilina se mostrou tão eficiente quanto a heparina na indução da reação acrossômica, no entanto, quando testada no meio de fecundação em bovinos, resultou em menores taxas de produção embrionária, tanto isolada quanto associada à heparina. 


\section{AGRADECIMENTOS}

À Fapemig (Fundação de Amparo à Pesquisa de Minas Gerais) e à Capes (Coordenação de Aperfeiçoamento de Pessoal de Nível Superior).

\section{REFERÊNCIAS}

ASSUMPÇÃO, M.E.; HAIPECK, O.D.; LIMA, K.A. et al. Capacitação espermática in vitro com heparina e cálcio ionóforo e sua correlação com a fertilidade em touros. Braz. J. Vet. Res. Anim. Sci., v.39, p.149-156, 2002.

BARTH, A.D.; OKO, R.J. Preparation of sêmen for morphological examination. In: BARTH, A.D.; OKO, R.J. Abnormal morphology of bovine spermatozoa. Ames, Iowa: Iowa State University, 1989. p.8-18.

CHIAN, R.C.; NAKAHARA, H.; KIWA, K.; FUNAHASHI, H. Fertilization and early cleavage in vitro of ageing bovine oocytes after maturation in culture. Theriogenology, v.37, p.665-672, 1992.

COELHO, L.A.; ESPER, C.R.; GARCIA, J.M. et al. Avaliação das condições de maturação oocitária e do efeito do reprodutor na produção in vitro de embriões bovinos. Braz. J. Vet. Res. Anim. Sci., v.35, p.120-122, 1998.

DIDION, B.A.; DOBRINSKI, J.R.; GILES, J.R.; GRAVES, C.N. Staining procedure to detect viability and the true acrosome reaction in spermatozoa of various species. Gamete Res., v.22, p.51-57, 1989.

FOLHADELLA, I.M. Perfil proteico do sêmen e fertilidade de touros da raça Gir. 2008. 66f. Tese (Doutorado em Ciência Animal) - Escola de Veterinária, Universidade Federal de Minas Gerais, Belo Horizonte, MG.

GORDON I. Oocyte recovery and maturation. In: GORDON I. Laboratory production of cattle embryos. Wallingford: CAB International, 1994. p.30-65.

KANG, S.S.; KOYAMA, K.; HUANG, W. et al. Addition of D-penicillamine, hypotaurine, and epinephrine (PHE) mixture to IVF medium maintains motility and longevity of bovine sperm and enhances stable production of blastocysts in vitro. J Reprod. Dev., v.61, p.99-105, 2015.
MANJUNATH, P.; THERIEN, I. Role of seminal plasma phospholipid binding proteins in sperm membrane lipid modification that occurs during capacitation. J. Reprod. Immunol., v.53, p.109-119, 2002.

MEIZEL, S.; TURNER, K.O. Chloride efflux during the progesterone-initiated human sperm acrosome reaction is inhibited by lavendustin A, a tyrosine kinase inhibitor. J. Androl., v.17, p.327-330, 1996.

MEMILI, E.; DOMINKO, T.; FIRST, N.L. Onset of transcription in bovine oocytes and preimplantation embryos. Mol. Reprod. Dev., v.51, p.36-41, 1998.

PARRISH, J.J. Bovine in vitro fertilization: in vitro oocyte maturation and sperm capacitation with heparin. Theriogenology, v.81, p.67-73, 2014.

PARRISH, J.J.; KROGENAES, A.; SUSKOPARRISH, J.L. Effect of bovine sperm separation by either swim-up or Percoll method on success of in vitro fertilization and early embryonic development. Theriogenology, v.44, p.859-869, 1995.

PARRISH， J.J.; SUSKO-PARRISH， J.L.; FIRST, N.L. Effect of heparin and chondroitin sulfate on the acrosome reaction and fertility of bovine sperm in vitro. Theriogenology, v.24, p.537-549, 1985.

PARRISH, J.J.; SUSKO-PARRISH, J.L.; WINER, M.A.; FIRST, N.L. Capacitation of bovine sperm by heparin. Biol. Reprod., v.38, p.1171-1180, 1988 .

PAUWELS, R.A.; BUIST, A.S.; CALVERLEY, P.M. et al. Gold Scientific Committe. Global strategy for the diagnosis, management, and prevention of chronic obstructive pulmonary disease. NHLBI/WHO Global Initiative for Chronic Obstructive Lung Disease (GOLD) Workshop summary. Am. J. Respir. Crit. Care Med. v.163, p.1256-1276, 2001.

PUGH, P.A.; TERVIT, H.R.; NIEMANN, H. Effects of vitrification medium composition on the survival of bovine in vitro produced embryos following in straw dilution in vitro and in vivo following transfer. Anim. Reprod. Sci., v.58, p.922,2000 . 
RAMOS, A.A.; CAMARGO, L.S.A.; SÁ, W.F. et al. Fecundação in vitro com sêmen de bovinos da raça Gir. Arq. Bras. Med. Vet. Zootec., v.52, p.360-365, 2000.

SOUSA, P.A.; WESTHUSIN, M.E.; WATSON, A.J. Analysis of variation in relative mRNA abundance for specific gene transcripts in single bovine oocytes and early embryos. Mol. Reprod. Develop., v.49, p.119-130, 1998.

STATISTICAL analysis system. Versão 9.2. Cary: SAS Institute, 2008.

TAKAHASHI, Y.; FIRST, N.L. In vitro fertilization of bovine oocytes in the presence of theophylline. Anim. Reprod. Sci., v.34, p.1-18, 1993.

TARTAGLIONE, C.M.; RITTA, M.N. Prognostic value of spermatological parameters as predictors of in vitro fertility of frozen-thawed bull semen. Theriogenology, v.62, p.1245-1252, 2004.
TESARIK, J.; THEBAULT, A.; TESTART, J. Effect of pentoxifylline on sperm movement characteristics in normozoospermic and asthenozoospermic specimens. Hum. Reprod., v.7, p.1257-1263, 1992.

VIANA, J.H.M.; CAMARGO, L.S.A.; FERREIRA, A.M. et al. Short intervals between ultrasonographically guided follicle aspiration improve oocyte quality but do not prevent establishment of dominant follicles in the Gir breed (Bos indicus) of cattle. Anim. Reprod. Sci., v.84, p.1-12, 2004.

YOSHIOKA, K.; SUZUKI, C.; ITOH, S. et al. Production of piglets derived from in vitroproduced blastocysts fertilized and cultured in chemically defined media: effects of theophylline, adenosine, and cysteine during in vitro fertilization. Biol. Reprod., v.69, p.20922099, 2003. 